\title{
STUDI EKSPERIMEN PENGARUH MEDAN MAGNET 800 GAUSS PADA ALIRAN BAHAN BAKAR PERTAMAX TERHADAP UNJUK KERJA MESIN BENSIN 150 CC
}

\author{
Agus Harianto $^{1}$, M. Arif Hariyadi ${ }^{2}$, Edi Kurniawan Prasetyo ${ }^{3}$ \\ 1) Staf Pengajar Teknik Mesin Universitas Antakusuma \\ Email: agus.harianto80@gmail.com, HP. 085234166861 \\ 2) Staf Pengajar Teknik Mesin Universitas Antakusuma \\ 3) Mahasiswa Teknik Mesin Universitas Antakusuma
}

\begin{abstract}
Intisari- Medan magnet dapat membantu proses ionisasi pada bahan bakar, sehingga bahan bakar saat proses pembakaran dapat mudah mengikat oksigen. Pengikatan oksigen pada bahan bakar secara stoikiometri menyebabkan pembakaran lebih sempurna, sehingga torsi dan daya pada mesin dapat meningkat. Tujuan dari penelitian ini adalah untuk mengetahui pengaruh pemasangan magnet 800 gauss terhadap torsi, daya, dan konsumsi bahan bakar spesifik motor bensin $150 \mathrm{CC}$. Penelitian ini dilakukan dengan membandingkan prestasi mesin motor bensin merk Honda Verza CW 150 CC yang dipasang magnet 800 Gauss merk X-Power pada saluran bahan bakar dengan tanpa dipasang magnet 800 Gauss merk X-Power. Setiap pengujian dilakukan pada putaran mesin $3000 \mathrm{rpm}, 4000 \mathrm{rpm}, 5000 \mathrm{rpm}, 6000 \mathrm{rpm}$, dan $7000 \mathrm{rpm}$. Metode yang digunakan adalah secara eksperimen di Laboratorium Efisiensi dan Konversi Energi. Hasil penelitian menunjukkan bahwa dengan menggunakan magnet 800 gauss terjadi peningkatan torsi maksimal sebesar 0,59\%, dan peningkatan daya maksimal sebesar $1 \%$.
\end{abstract}

Kata kunci- Magnet 800 gauss, torsi, daya, konsumsi bahan bakar spesifik.

\section{PENDAHULUAN}

Bahan bakar minyak (BBM) berperan sangat penting dalam perkembangan teknologi, terutama dalam bidang teknologi industri dan otomotif. Penggunaan bahan bakar minyak semakin hari semakin meningkat, namun di sisi lain minyak mentah semakin berkurang. Berkurangnya bahan bakar dan meningkatnya kebutuhan bahan bakar membuat bahan bakar semakin mahal. Untuk itu perlu penghematan pemakaian bahan bakar dan meningkatkan kualitas pembakaran. Salah satu cara yang digunakan untuk menghemat dan meningkatkan kualitas bahan bakar minyak adalah dengan penggunaan magnet.

Alim Kurnia Ismawan, dkk (2010) dalam penelitiannya menggunakan magnet merk Femax Combo pada mesin $110 \mathrm{CC}$, didapatkan hasil meningkatnya torsi dan daya, dan mereduksi konsumsi bahan bakar sebesar 5,45\%. Riccy Kurniawan (2009) hasil penelitian menunjukan bahwa motor bensin yang terkena medan magnet yang ditimbulkan oleh magnet-X menghasilkan emisi gas buang yang lebih ramah lingkungan, peningkatan efisiensi mesin yang terlihat pada daya dan torsi yang meningkat cukup signifikan disertai penghematan konsumsi bahan bakar. Tjin Rudy (2005) hasil penelitian menunjukan bahwa dalam peningkatan unjuk kerja mesin dengan perlakuan medan magnet antara lain peningkatan daya maksimum sebesar 4,7\%, penurunan pemakaian bahan bakar spesifik maksimum sebesar 11,8\%, peningkatan efisiensi thermis maksimum sebesar $13,4 \%$ dan penurunan kadar CO maksimum sebesar 25\%. Sehingga dapat disimpulkan adanya perlakuan medan magnet dapat meningkatkan unjuk kerja mesin.

\section{TINJAUAN PUSTAKA}

\section{A. Motor Bensin}

Motor Otto atau Beau de Roches meru- pakan mesin pengonversi energi tidak langsung, yaitu dari energi kimia bahan bakar menjadi energi panas dan baru kemudian menjadi energi kinetik.

Berdasarkan siklus kerjanya, motor bensin dibedakan menjadi dua, yaitu :

a) Motor bensin dua langkah (Two Stroke) Motor bensin dua langkah adalah motor yang pada dua langkah piston (satu putaran poros engkol) sempurna akan menghasilkan satu langkah kerja.

b) Motor bensin empat langkah (Four Stroke) Motor bensin empat langkah adalah motor yang pada setiap empat langkah piston (dua putaran poros engkol) sempurna, meng- hasilkan satu tenaga kerja (satu langkah kerja). 
Proses teoritis motor bensin adalah proses yang bekerja berdasarkan siklus Otto, dimana proses pemasukan kalor berlangsung pada volume konstan.

Sedangkan siklus aktual yang terjadi pada motor bensin, efisiensinya jauh lebih rendah daripada efisiensi siklus ideal, karena berbagai kerugian yang terjadi dalam operasi mesin.

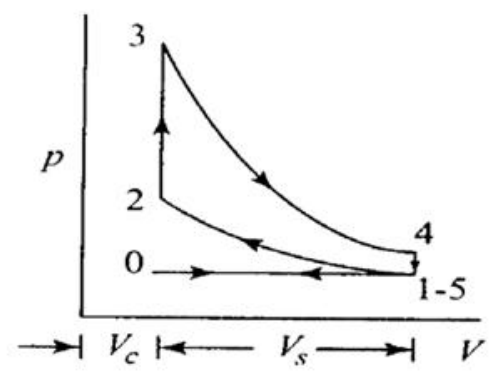

Gambar 1. Siklus Ideal Motor Bensin Empat Langkah

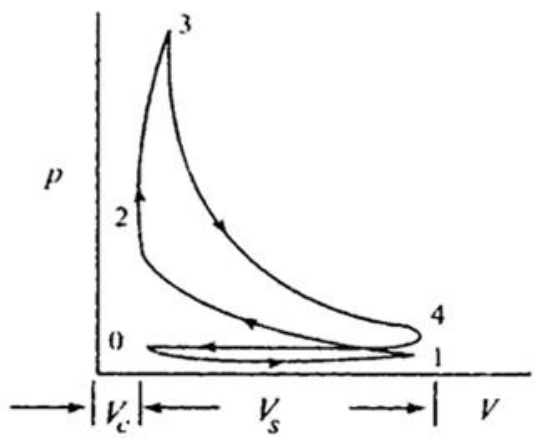

\section{Gambar 2. Siklus Aktual Motor Bensin Empat} Langkah

Sistem bahan bakar pada sepeda motor terdiri dari sistem suplai bahan bakar dan sistem penakar bahan bakar. Sistem suplai bahan bakar berfungsi mengalirkan bahan bakar dari tangki ke sistem penakar bahan bakar. Sedangkan sistem penakar bahan bakar berfungsi untuk menakar jumlah udara dan bahan bakar agar diperoleh campuran udarabahan bakar yang dapat dibakar dengan cepat dan sempurna di dalam silinder dan juga berfungsi untuk atomisasi dan penyebar bahan bakar di dalam aliran udara.

\section{B. Teori Kemagnetan}

Macam-macam bahan ditinjau dari sifat kemagnetannya ada tiga macam, yaitu: a) Feromagnetik adalah bahan yang menimbulkan sifat kemagnetan yang kuat di bawah pengaruh medan magnet dari luar.

b) Paramagnetik adalah bahan yang menunjukkan sifat kemagnetan lemah dibawah pengaruh medan magnet dari luar.

c) Diamagnetik adalah bahan yang sedikit melawan penga- ruh sifat kemagnetan dari pengaruh medan magnet dari luar.

\section{Teori Katalisator Bensin}

Cara kerja katalisator bensin adalah dengan menggunakan sistem kemagnetan, yaitu dengan pemberian suatu medan magnet pada saluran bahan bakar yang menuju karburator. Sebelum masuk ke ruang bakar, bensin mengalami restrukturisasi ion positif dan negatif agar lebih mudah terbakar di dalam silinder.

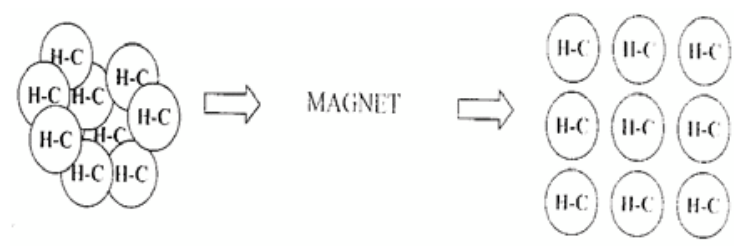

Gambar 3. Efek Kemagnetan

Molekul hidrokarbon merupakan unsur penyusun utama bensin, cenderung untuk saling tertarik satu sama lain, membentuk gugus molekul (clustering). Pemberian suatu medan magnet pada molekul hidrokarbon tersebut menyebabkan penolakan - penola-kan antar molekul hidrokarbon (declustering), sehingga terbentuk jarak yang optimal antara molekul hidrokarbon dan melemahkan ikatan antara atom $\mathrm{HC}$ dan mudah tertarik dengan oksigen pada proses pembakarannya.

Dengan adanya hal tersebut di atas, bahan bakar yang terkena efek kemagnetan akan menjadi semakin reaktif dalam proses pembakaran yang sempurna di ruang pem-bakaran, sehingga akan mempengaruhi unjuk kerja mesin yang semakin meningkat.

D. Parameter - parameter Performa Mesin

Kendaraan Bermotor

Parameter performa mesin kendaraan bermotor antara lain:

- Torsi (Torque)

$$
\mathrm{T}=\mathrm{F} \cdot \mathrm{r} \quad \text { (N.m) }
$$

Keterangan:

$\mathrm{T}=$ Torsi (N.m)

$\mathrm{F}$ = Gaya yang bekerja pada torak $(\mathrm{N})$

$\mathrm{r} \quad=$ Panjang lengan poros (crank arm $1 / 2$ langkah torak) (m) 
- Daya

$$
\mathrm{P}=2 \pi \times n \times T
$$

... (2)

Keterangan:

$\mathrm{P} \quad=$ Daya poros $(\mathrm{KW})$

$\mathrm{T} \quad=$ Torsi (N.m)

$\mathrm{N} \quad=$ Putaran mesin (rpm)

- Konsumsi Bahan Bakar Spesifik (Sfc)

1) $\quad s f c=\frac{\dot{m}_{f}}{P}$

... (3)

Keterangan:

$\dot{m}_{f} \quad$ Laju aliran massa bhn bakar $\left(\frac{\mathrm{kg}}{\mathrm{s}}\right)$

$\mathrm{P} \quad=$ daya poros $(\mathrm{KW})$

\section{METODE}

Metode yang dilakukan selama penelitian ini adalah sebagai berikut:

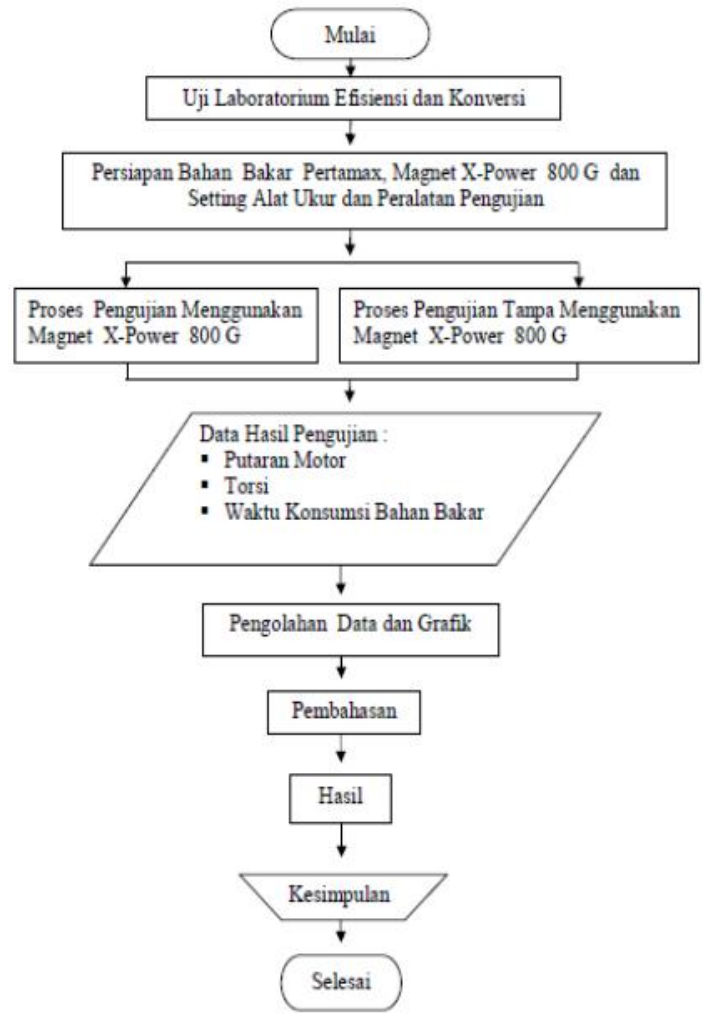

\section{Gambar 3. Diagram Alir Penelitian}

\section{A. Alat Penelitian}

Peralatan yang digunakan selama penelitian ini adalah:

1. Mesin sepeda motor $150 \mathrm{cc}$
Tabel 1. Data Spesifikasi Sepeda Motor

\begin{tabular}{|c|c|}
\hline \multicolumn{2}{|l|}{ TIPE } \\
\hline Merk & Verza $150 \mathrm{CW}$ \\
\hline \multicolumn{2}{|l|}{ DIMENSI } \\
\hline $\begin{array}{l}\text { Panjang } \mathrm{x} \text { Lebar } \mathrm{x} \\
\text { Tinggi }\end{array}$ & $\begin{array}{lllll}\begin{array}{l}2.056 \\
\mathrm{~mm}\end{array} & \mathrm{x} & 742 & \mathrm{x} & 1.054 \\
\end{array}$ \\
\hline Jarak Sumbu Roda & $1.318 \mathrm{~mm}$ \\
\hline $\begin{array}{lll}\text { Jarak terendah } & \text { ke } \\
\text { tanah } & & \\
\end{array}$ & $156 \mathrm{~mm}$ \\
\hline Berat kosong & $129 \mathrm{~kg}$ \\
\hline $\begin{array}{l}\text { Kapasitas tangki } \\
\text { bahan bakar }\end{array}$ & 12,2 liter \\
\hline \multicolumn{2}{|l|}{ MESIN } \\
\hline Mesin & $\begin{array}{l}4 \text { Langkah, SOHC, } \\
\text { Silinder Tunggal }\end{array}$ \\
\hline Volume langkah & $149,2 \mathrm{cc}$ \\
\hline Diameter x Langkah & $57,3 \times 57,8$ \\
\hline $\begin{array}{l}\text { Perbandingan } \\
\text { Kompresi }\end{array}$ & $9,5: 1$ \\
\hline Daya maksimum & $\begin{array}{l}9,72 \mathrm{Kw}(13,2 \mathrm{PS}) / \\
8.500 \mathrm{Rpm}\end{array}$ \\
\hline Torsi maksimum & $\begin{array}{l}12,7 \mathrm{Nm}(1,29 \text { kgf.m }) / \\
6.000 \mathrm{Rpm}\end{array}$ \\
\hline $\begin{array}{l}\text { Kapasitas minyak } \\
\text { pelumas mesin }\end{array}$ & $\begin{array}{l}1,0 \quad \text { liter pada } \\
\text { penggantian periodik }\end{array}$ \\
\hline Tipe Kopling & $\begin{array}{l}\text { Manual, multiplate wet } \\
\text { clutch }\end{array}$ \\
\hline Tipe transmisi & 5 kecepatan \\
\hline Pola pengoperan gigi & $1-N-2-3-4-5$ \\
\hline Tipe starter & $\begin{array}{l}\text { Starter kaki dan starter } \\
\text { elektrik }\end{array}$ \\
\hline \multicolumn{2}{|l|}{ KELISTRIKAN } \\
\hline Tipe battery & $12 \mathrm{~V}-3,5 \mathrm{Ah}$ \\
\hline Busi & NGK CPR9EA-9 \\
\hline Pengapian & Full Transisterized \\
\hline
\end{tabular}

2. Dynamometer (type disk brake)

3. Buret Ukur

4. Stopwatch

5. Kipas Pendingin

6. Proximity Sensor

\section{B. Bahan Penelitian}

Bahan yang digunakan dalam penelitian ini adalah sebagai berikut:

1. Medan Magnet $800 \mathrm{G}$

Prinsif kerja Magnet $800 \mathrm{G}$ menggunakan gelombang active ultra magnetics yang dihasilkan dari susunan beberapa komponen magnet permanent dengan formulasi khusus. 


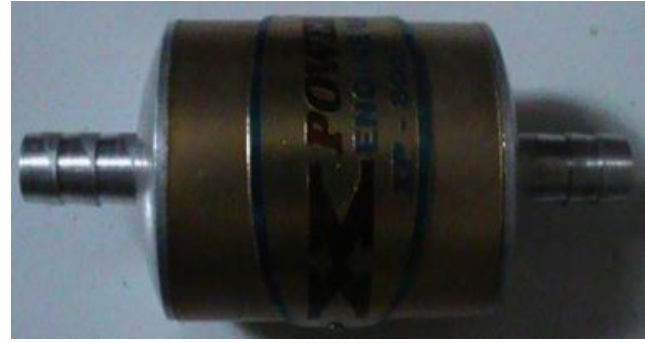

Gambar 4. Magnet 800 G

2. Bahan Bakar Pertamax RON 92

Bahan bakar yang digunakan selama penelitian ini adalah bahan bakar yang dipasarkan oleh PT. Pertamina dengan angka oktan (RON) sebedar 92. Adapun data fisik dan kimiawi untuk bahan bakar ini dapat dilihat pada tabel 2 .

\section{Prosedur Penelitian}

Prosedur yang dilaksanakan dalam melakukan penelitian dapat dijabarkan sebagai berikut:

a. Motor start

b. Persneling posisi gigi ke- 5

c. Trotel diputar sampai putaran engine $7000 \mathrm{rpm}$.

d. Tunggu stabil kemudian data diambil dengan tahapan :

- Catat angka yang tampil pada display. Angka yang tampil pada display dianggap nol karena belum ada pembebanan (pengereman). Hal itu terjadi karena pengaruh gesekan dan gaya momen inersia alat.

- Tempel anemometer pada saluran udara masuk, catat angka yang tampil.

- Perhatikan penurunan bahan bakar pada buret sambil mengukur waktu penurunan menggunakan stopwatch. Pada garis ke 5, berhenti mengukur waktunya, catat

e. Matikan mesin, tunggu dingin.

f. Setelah normal, mesin hidupkan, prosedur 3 dilakukan

g. Lakukan pembebanan dengan menekan caliper rem. Penekanan diatur sampai RPM engine menunjukkan RPM 7000.

h. Tunggu stabil kemudian data diambil dengan tahapan :

- Catat angka yang tampil pada display.

- Tempel anemometer pada saluran udara masuk, catat angka yang tampil.

- Perhatikan penurunan bahan bakar pada buret sambil mengukur waktu penurunan menggunakan stopwatch. Pada garis ke 5, berhenti mengukur waktunya, catat

Tabel 2. Data fisik dan kimiawi bahan bakar pertamax

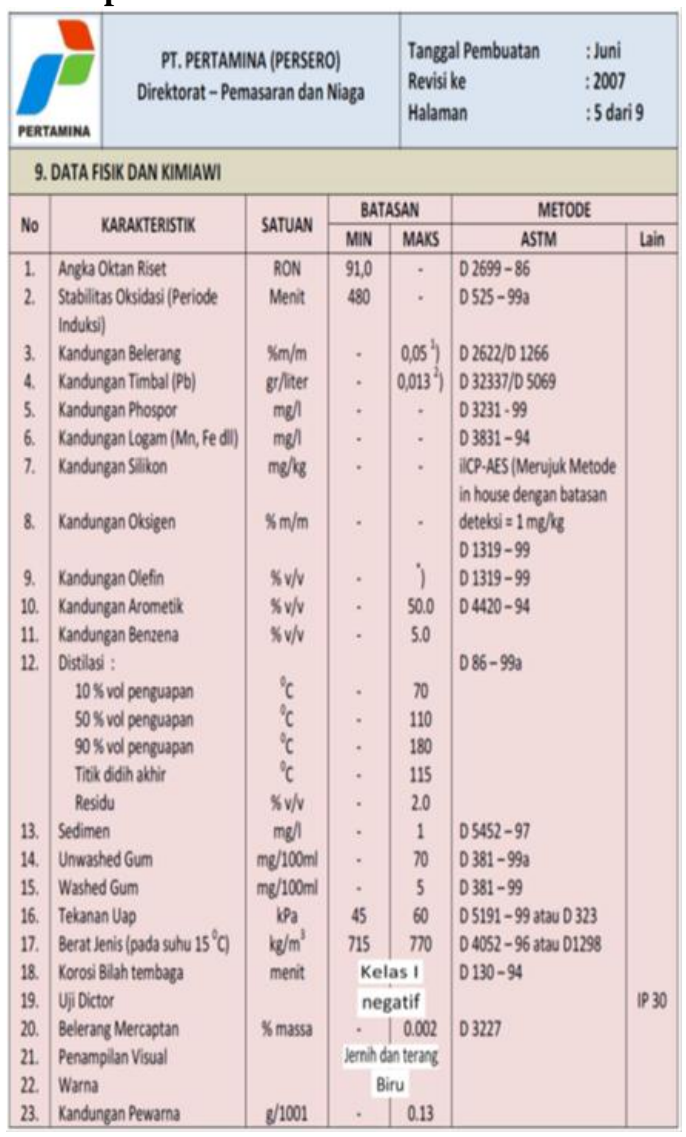

i. Mesin matikan kembali, menunggu mesin dingin.

j. Lakukan prosedur $6,7,8$, dengan beban pengereman bervariasi dari RPM 7000, 6000, 5000, 4000, 3000.

\section{HASIL DAN PEMBAHASAN}

\section{A. Torsi}

Berdasarkan hasil pengujian pada gambar 5 menjelaskan torsi pada penggunaan tanpa medan magnet (standar) dan yang menggunakan medan magnet X-Power $800 \mathrm{G}$.

Tabel 3. Data Hasil Pengujian Tanpa Medan Magnet (Standar) 


\begin{tabular}{|c|c|c|c|}
\hline $\begin{array}{c}\text { Putaran } \\
\text { Mesin } \\
(\text { Rpm) }\end{array}$ & \multirow{2}{*}{$\begin{array}{l}\text { Torsi } \\
(\mathbf{N m})\end{array}$} & \multicolumn{2}{|c|}{$\begin{array}{c}\text { Konsumsi bahan } \\
\text { bakar }\end{array}$} \\
\cline { 3 - 4 } & & $\begin{array}{c}\text { Miter } \\
(\mathbf{m l})\end{array}$ & Detik (s) \\
\hline 3000 & 11,82 & 5,2 & 7,07 \\
\hline 4000 & 11,88 & 5 & 6,09 \\
\hline 5000 & 11,96 & 4 & 5,13 \\
\hline 6000 & 12,05 & 3,4 & 5,09 \\
\hline 7000 & 11,97 & 3 & 4,09 \\
\hline
\end{tabular}

Tabel 4. Data Hasil Pengujian Medan Magnet X-Power 800 G

\begin{tabular}{|l|l|l|l|}
\hline \multirow{2}{*}{$\begin{array}{c}\text { Putaran } \\
\text { Mesin } \\
(\text { Rpm) }\end{array}$} & \multirow{2}{*}{$\begin{array}{c}\text { Torsi } \\
\text { (Nm) }\end{array}$} & \multicolumn{2}{|c|}{$\begin{array}{c}\text { Konsumsi bahan } \\
\text { bakar }\end{array}$} \\
\cline { 3 - 4 } & & $\begin{array}{c}\text { mili } \\
\text { liter } \\
\text { (ml) }\end{array}$ & detik (s) \\
\hline 3000 & 11,89 & 3,66 & 8,38 \\
\hline 4000 & 11,95 & 3,43 & 7,77 \\
\hline 5000 & 12,03 & 3,4 & 7,31 \\
\hline 6000 & 12,09 & 2,73 & 4,9 \\
\hline 7000 & 12,00 & 2,46 & 3,33 \\
\hline
\end{tabular}

Dari tabel 3 dan 4 didapatkan torsi sebagai berikut:

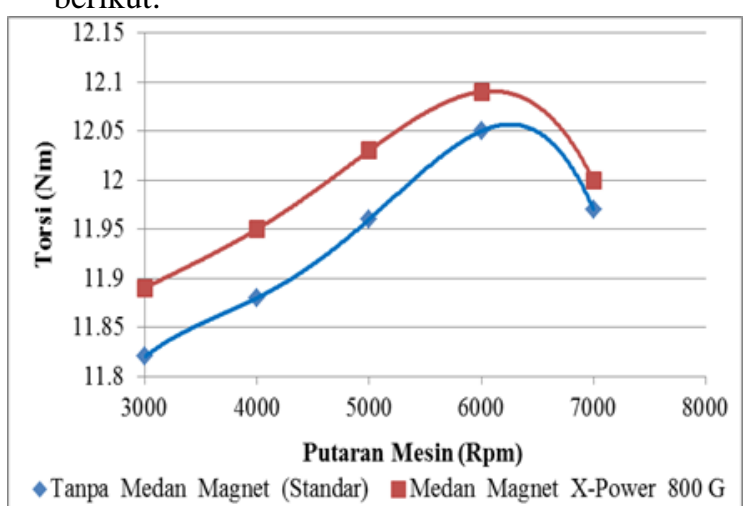

Gambar 5. Grafik Putaran Mesin terhadap Torsi

Semakin rpm dinaikan torsi pada penggunaan medan magnet X-Power $800 \mathrm{G}$ mengalami kenaikan pada putaran 3000 - 6000 rpm dengan nilai rata-rata $11,99 \mathrm{Nm}$ dan mengalami penurunan di $7000 \mathrm{rpm}$ dengan nilai 12,00 Nm. Sedangkan torsi pada penggunaan tanpa medan magnet (standar) mengalami kenaikan pada putaran 3000 - $6000 \mathrm{rpm}$ dengan nilai ratarata $11,92 \mathrm{Nm}$ dan mengalami penurunan di 7000 rpm dengan nilai 11,97 Nm. Hal ini disebabkan karena kerugian gesekan (friction loss) meningkat dengan bertambahnya putaran mesin dan menjadi faktor dominan pada putaran mesin yang lebih tinggi
(Pulkrabel, 1997 hal. 52). Hasil pengujian dari gambar grafik perbedaan torsi penggunaan medan magnet X-Power $800 \mathrm{G}$ dan tanpa medan magnet (standar), motor dalam pengujian menggunakan medan magnet X-Power $800 \mathrm{G}$ memiliki torsi yang lebih tinggi dari pada motor yang tanpa menggunakan medan magnet (standar). Kenaikan torsi disebabkan oleh kandungan oktan yang tinggi pada bahan bakar pertamax 92 dan proses magnetisasi pada bahan bakar akan membuat pembakaran lebih sempurna.

\section{B. Daya}

Tabel 5. Hasil Perhitungan Daya Poros

\begin{tabular}{|l|l|l|}
\hline $\begin{array}{l}\text { Putaran } \\
\text { Mesin } \\
\text { (Rpm) }\end{array}$ & $\begin{array}{l}\text { Tanpa } \\
\text { Magnet } \\
\text { (standar) } \\
(\mathbf{k W})\end{array}$ & $\begin{array}{l}\text { Dengan } \\
\text { Magnet } \\
\mathbf{8 0 0 G} \\
(\mathbf{k W})\end{array}$ \\
\hline 3000 & 3,6957 & 3,7334 \\
\hline 4000 & 4,9737 & 5,0025 \\
\hline 5000 & 6,2590 & 6,2954 \\
\hline 6000 & 7,5674 & 7,5925 \\
\hline 7000 & 8,7700 & 8,7914 \\
\hline
\end{tabular}

Dari tabel 5 didapatkan grafik daya sebagai berikut :

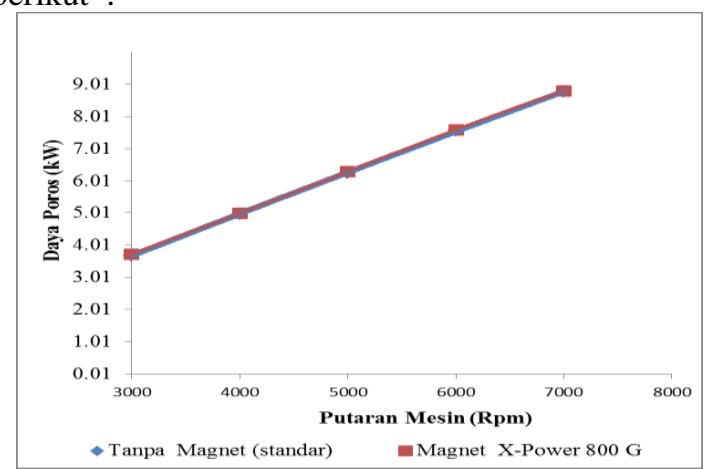

Gambar 6. Grafik Putaran Mesin terhadap Daya Poros

Berdasarkan gambar 6 menunjukan bahwa adanya perbedaan antara daya yang mengguna-kan medan magnet X-Power $800 \mathrm{G}$ dan tanpa medan magnet (standar). Semakin rpm dinaikan, daya pada penggunaan medan magnet X-Power $800 \mathrm{G}$ mengalami kenaikan pada putaran 3000 - 7000 rpm dengan nilai rata-rata $6,2830 \mathrm{~kW}$. Sedangkan daya pada penggunaan tanpa medan magnet (standar) mengalami kenaikan pada putaran 3000 - $7000 \mathrm{rpm}$ dengan nilai rata-rata 6,2531 kW.

Kesimpulan dari gambar grafik perbedaan daya pada penggunaan medan magnet X-Power $800 \mathrm{G}$ dan tanpa medan magnet (standar), motor dalam pengujian menggunakan medan magnet $\mathrm{X}$ - 
Power $800 \mathrm{G}$ memilik daya yang lebih besar dibandingkan motor yang tanpa menggunakan medan magnet (standar).

\section{Specifik Fuel Consumption (SFC)}

Dari tabel 5 didapatkan grafik Specific Fuel Consumption (sfc) sebagai berikut:

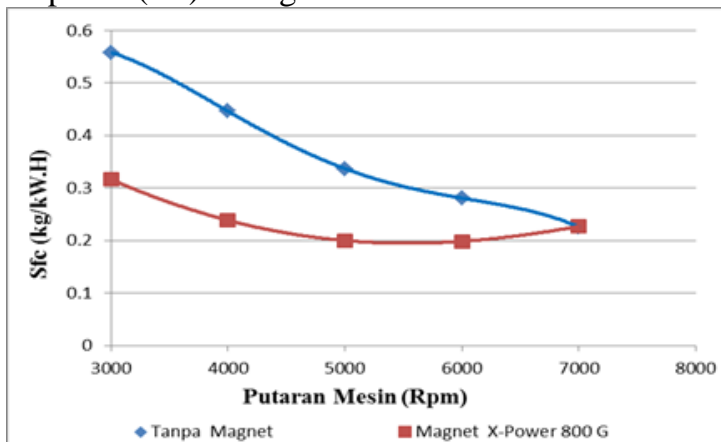

Gambar 7. Putaran Mesin Vs Specifik Fuel Consumption (SFC)

Pada gambar 7 menunjukan perban-dingan antara putaran mesin dengan konsumsi bahan bakar spesifik (sfc) yang dihasilkan dari data hasil pengujian tanpa medan magnet (standar) dengan menggunakan medan magnet X-Power $800 \mathrm{G}$. Semakin rpm dinaikan konsumsi bahan bakar spesifik (sfc) pada penggunaan medan magnet XPower $800 \mathrm{G}$ mengalami penurunan pada putaran 3000 - $6000 \mathrm{rpm}$ dengan nilai rata-rata sebesar $0,2382 \mathrm{~kg} / \mathrm{Kwh}$ dan mengalami kenaikan di 7000 rpm dengan nilai 0,2271 kg/Kwh. Sedangkan konsumsi bahan bakar spesifik (sfc) pada penggunaan tanpa medan magnet (standar) mengalami penurunan pada putaran 3000 - 6000 rpm dengan nilai rata-rata $0,4005 \mathrm{~kg} / \mathrm{Kwh}$ dan mengalami kenaikan pada putaran di $7000 \mathrm{rpm}$ dengan nilai $0,2836 \mathrm{~kg} / \mathrm{Kwh}$.

Semakin tinggi kecepatan mesin maka konsumsi bahan bakar juga akan semakin meningkat sedangkan kenaikan daya tidak signifikan dan mulai kembali turun seperti pada gambar 7. Hal ini disebabkan karena pada kecepatan tinggi, kerugian gesekan (friction loss) akan lebih besar sehingga konsumsi bahan bakar juga meningkat (Pulkrabek, 1997 hal. 57). Besarnya nilai sfc pada puataran rendah juga dipengaruhi oleh pasokan udara kedalam ruang bakar, dimana pada putaran rendah pasokan udara yang masuk kedalam ruang bakar lebih sedikit, sehingga pembakaran lebih kaya yang menyebabkan daya pada mesin berkurang. Pembakaran kaya merupakan faktor utama yang menyebabkan nilai sfc pada mesin meningkat.
Kesimpulan dari gambar 7, perbeda-an konsumsi bahan bakar spesifik (sfc) pada penggunaan medan magnet X-Power $800 \mathrm{G}$ dan tanpa medan magnet (standar), motor dalam pengujian menggu-nakan medan magnet X-Power $800 \mathrm{G}$ memilik konsumsi bahan bakar spesifik (sfc) yang lebih rendah dibandingkan motor yang tanpa menggunakan medan magnet (standar).

\section{KESIMPULAN}

Semakin rpm dinaikan, maka torsi mesin pada penggunaan medan magnet X-Power $800 \mathrm{G}$ mengalami kenaikan pada putaran 3000 - $6000 \mathrm{rpm}$ dengan nilai rata-rata $11,99 \mathrm{Nm}$ dan mengalami penurunan di $7000 \mathrm{rpm}$ dengan nilai 12,00 Nm. Sedangkan torsi pada penggunaan tanpa medan magnet (standar) mengalami kenaikan pada putaran 3000 - $6000 \mathrm{rpm}$ dengan nilai rata-rata 11,92 $\mathrm{Nm}$ dan mengalami penurunan di $7000 \mathrm{rpm}$ dengan nilai $11,97 \mathrm{Nm}$.

Semakin rpm dinaikan, maka daya mesin pada penggunaan medan magnet X-Power $800 \mathrm{G}$ mengalami kenaikan pada putaran 3000 - $7000 \mathrm{rpm}$ dengan nilai rata-rata $6,2830 \mathrm{~kW}$. Sedangkan daya pada penggunaan tanpa medan magnet (standar) mengalami kenaikan pada putaran 3000 - 7000 rpm dengan nilai rata-rata $6,2531 \mathrm{~kW}$.

Semakin rpm dinaikan konsumsi bahan bakar spesifik (sfc) mesin, pada penggunaan medan magnet X-Power $800 \mathrm{G}$ mengalami penurunan pada putaran 3000 - $6000 \mathrm{rpm}$ dengan nilai rata-rata sebesar $0,2382 \mathrm{~kg} / \mathrm{Kwh}$ dan mengalami kenaikan di 7000 rpm dengan nilai $0,2271 \mathrm{~kg} / \mathrm{Kwh}$. Sedangkan konsumsi bahan bakar spesifik (sfc) pada penggunaan tanpa medan magnet (standar) mengalami penurunan pada putaran 3000 - $6000 \mathrm{rpm}$ dengan nilai rata-rata $0,4005 \mathrm{~kg} / \mathrm{Kwh}$ dan mengalami kenaikan pada putaran di $7000 \mathrm{rpm}$ dengan nilai $0,2836 \mathrm{~kg} / \mathrm{Kwh}$.

\section{DAFTAR PUSTAKA}

[1] Arends,BPM \& Berenscot H.1980, Motor Bensin, Alih Bahasa : Umar Sukrisno Penerbit Erlangga, Jakarta

[2] Arismunandar, Wiranto, (2005), Penggerak Mula: Motor Bakar Torak, Penerbit ITB, Bandung..

[3] Bird, Tony. Kimia Fisik Untuk Universitas. Penerbit Gramedia

[4] Cengel, A. Yunus \& Boles, Micheal A. 1994, Thermodynamics An Engineering Approach, Mc Graw-Hill Book Inc., New York 
[5] Furguson, Colin R. 1986, Internal Combustion Engine -Applied hermossciences, Purdue university.

[6] Hardjono, A. 2001. Teknologi Minyak Bumi. Gadjah Mada University Press, Yogyakarta

[7] Heywood, J.B 1988, Internal Combustion Engine Fundamentals, Singapore: McGraw-Hill Book Co.

[8] Jurnal (2009) Riccy Kurniawan "Kaji Ekperimental Pengaruh

[9] Penggunaan Medan Magnet Terhadap Kinerja Motor Bensin diakses 12 Februari 2015.

[10] Ismawan,AK, dkk. 2010 "Pengaruh Pemasangan Alat Peningkat Kualitas Bahan Bakar Terhadap Unjuk Kerja Dan Konsumsi Bahan Bakar Spesifik Motor Bensin diakses 12 Februari 2015.

[11] Ropa, AK., Naif Fuhaid, Nova Risdiyanto Ismail, (2012), PROTON, Vol. 4 No 2/Hal 1 4

[12] "Performance of Spark Ignition Engine Under The Influence Of Magnetic Field diakses 12 Februari 2015.

[13] Maleev, V. L. 1983, International Critical Tables, vol. 1, Mc Graw- Hill Book Inc., New York

[14] Obert, Edward F, (1973), Internal Combustion Engines and Air Pollution, Harper \& Row, Publisher, Inc, New York.

[15] Pulkrabek, Willard W (1997), Internal Combustion Engine, Prentice Hall, New Jersey.

[16] Setiawan, Tjin Rudi. Studi Pengaruh Medan Magnet Pada Aliran Bahan Bakar Terhadap Unjuk Kerja Motor Bensin.

[17] Warju, (2009), Pengujian Performa mesin Kendaraan Bermotor, Unesa University Press, Surabaya

[18] www.X-Power.com di akses 12 Maret 2015

[19] www.pertamina.com di akses 14 Maret 2015

[20] www.astra-honda.com di akses 14 Maret 2015 
HALAMAN INI SENGAJA DIKOSONGKAN 